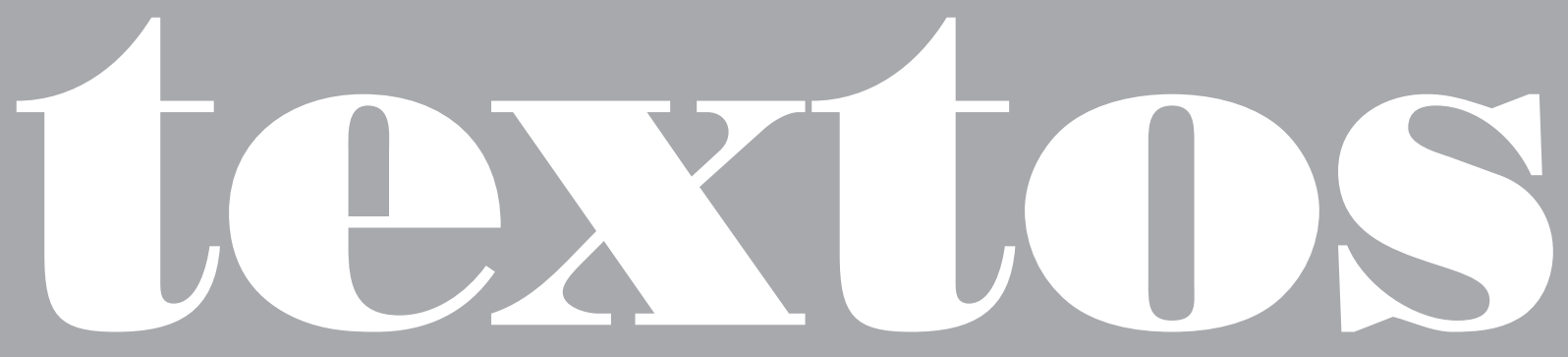





\title{
Espectros da multidão
}

\author{
Felipe Ziotti Narita
}

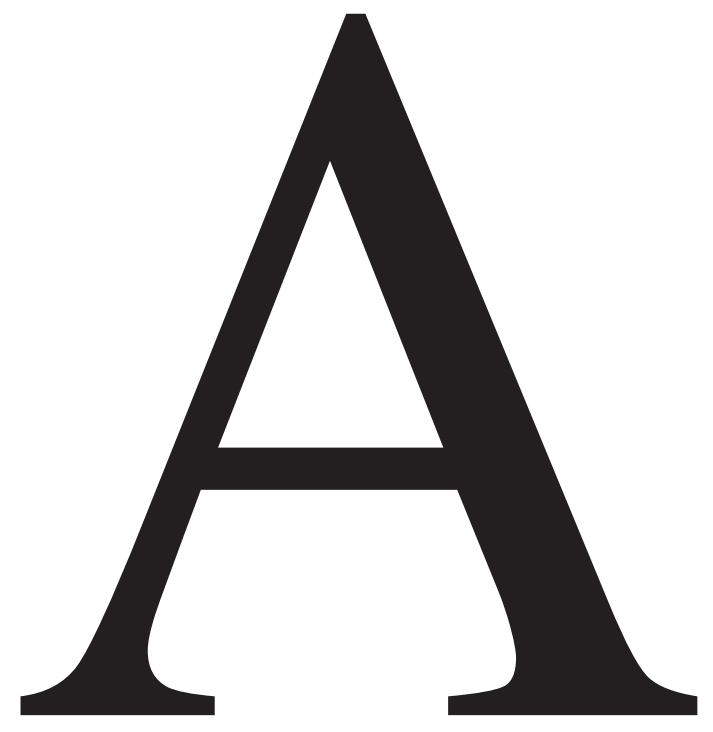

tematização e as análises sociológicas das massas da modernidade capitalista não são novas - remontam à segunda metade do século XIX e às primeiras décadas do $\mathrm{XX}$, com as narrativas de Dickens, as imagens de Walter Ruttmann e os textos de Le Bon e Ortega y Gasset. Além dos efeitos da aglomeração, o potencial irruptivo e a irracionalidade das turbas eram pautas importantes da vida urbana. Nesse sentido, mais do que um fenômeno da quantidade, as formas de ação coletiva da modernidade

FELIPE ZIOTTI NARITA é pesquisador da USP, pesquisador convidado da Universidade de Fribourg (Suíça)

e professor da pós-graduação na Unesp. 
conformaram sujeitos (Sloterdijk, 2016), colocando em movimento tanto reivindicações quanto narrativas identitárias do povo e de seu conteúdo moral.

Em livro clássico publicado em 1960, Elias Canetti (2001) caracteriza a massa moderna a partir da compactação de absoluta igualdade e homogeneidade de vontades engendrada pelo efeito concentracional (Dichte) dos indivíduos. A análise dessas estruturas da vida coletiva e de suas mobilizações ganha especial relevância em uma conjuntura entrecortada pela deflação dos movimentos sociais na América Latina (à luz da crise estrutural dos governos de esquerda e centro-esquerda na região a partir de 2016) e pela ressurgência do ultranacionalismo (vide as recentes mobilizações de massa na Macedônia, na Grécia e na Itália) junto à ascensão transnacional do populismo autoritário (com narrativas centradas na homogeneidade da nação) (Morelock \& Narita, 2018) e do avanço da extrema-direita na Áustria, na Alemanha, nos países pós-socialistas, nos Estados Unidos e na América Latina. Se as manifestações ultranacionalistas dos últimos três anos evidenciam uma pretensão de unificação e coesão de repertórios de mobilização de massa, as condições de compactação moral e unidade de ação sofreram inflexões diante das transformações materiais do mundo da vida.

Especialmente nesta década, um ciclo de coletivos e de revoltas nas praças e nas ruas sinalizou expressões significativas dessas mutações (Johnson \& Suliman, 2015). A desterritorialização dos fluxos de informação e a territorialização das mobilizações nas cidades demonstram a sobreposição de circuitos da modernidade global por meio dos quais a rua apareceu como espaço de produção de novas formas do social (Sassen, 2011). Nesse sentido, protestos urbanos, contando com a ocupação do espaço público e (em muitos casos) com violência, indicaram transformações importantes nos antigos fenômenos de massa: Reykjavík (2008-2009), Túnis (2010), as diversas manifestações do Occupy (20112012), Sófia (2013), o movimento Black Lives Matter, a profunda crise de representação escancarada nas ruas brasileiras de 2013, as mobilizações nas praças espanholas, egípcias e turcas, a plataforma romena Demos (2016) e os protestos de 2016 na França (com ênfase na difusão do Nuit Debout) sinalizaram condições desse "novo tempo do mundo" (Arantes, 2014) em que a fissura no tempo político foi levada a cabo pela potência coletiva de novas subjetividades políticas (Pelbart, 2013) favorecidas pela infraestrutura das redes e pela disseminação de um conjunto difuso de críticas à racionalidade neoliberal (Dardot \& Laval, 2016), à deterioração dos serviços públicos e aos impasses da representação e da confiança junto aos sistemas políticos e financeiros.

Vinculada à primazia das formas de vida compartilhadas, a nova imaginação política indicou espaços para um civismo situado além do pluralismo pós-moderno (Pabst, 2011) por meio do qual a absolutização do regime de diferenças implicava um bloqueio a narrativas razoavelmente unificadas por um comum. A partir dos diversos espectros do campo político-ideológico, houve dezenas de esforços dedicados ao entendimento dos sentidos fundamentais desse ciclo de revoltas urbanas e das formas associativas emergentes (destaco, por exemplo, as análises de Manuel Castells, Paul Mason, Angela Alonso, Ann Mische, Peter Beaumont, Thomas Carothers, Vladimir Safatle, Marco Aurélio Nogueira, 
Thomas Vicino, Richard Youngs, Alberto Aggio e Moisés Naím). Como narrativas, as mídias e a profusão de imagens, multiplicando os estampidos da aceleração do tempo disseminada nos smartphones e nas redes, alimentaram a dinâmica performativa das coletividades e a estética dos antagonismos como a mise-en-scène das contradições sociais emolduradas pela violência (Fischer, 2017).

As ambivalências das recentes manifestações coletivas, nuançadas por registros ideológicos do pacífico/violento e ordeiro/desordeiro, mobilizam um conjunto de percepções em relação à potencial desestabilização de estruturas de coesão social. Nesse sentido, como singularidades e multiplicidades em movimento, a multidão, por meio da dialética do medo/segurança (Virno, 2001), faz oposição à ideia de povo como unidade coerente. Creio que, aqui, uma linha de força deve ser considerada: a lógica pervasiva da violência e das bombas de gás (Kechavarzi-Tehrani, 2017; Feigenbaum, 2017) colocou a multidão e sua nova anatomia no centro do problema. O ciclo aberto em 2008, contudo, é apenas metade da história: subjacente às ruas e às multidões, uma conjuntura de sedimentação de críticas à racionalidade neoliberal e à predação rentista construiu repertórios fundamentais para a circulação de novos sujeitos (Narita, 2018).

O campo de investigações da multidão, consolidado nos anos 1990, é uma espécie de contranarrativa da globalização capitalista erigida na esteira da queda dos regimes coloniais e sobre os escombros do bloco soviético (Brantlinger, 2013). Não à toa, estudos fundamentais desse estado de coisas emergiram a partir das mobilizações altermundialistas (carregando diversas pautas autonomistas em relação às lógicas do Estado e à verticalização dos partidos) de Chiapas (1994), Seattle (1999), Washington (2000), Praga (2000), Gênova (2001) e Porto Alegre (2002). Se as reivindicações pelos comuns (Klein, 2002), entendidos como recursos compartilhados (praças, água, software, escolas, etc.) que são apropriados pelas estruturas de mercado, têm evidenciado os choques contra a mercantilização e a integração assimétrica do capitalismo global, as novas dinâmicas de mobilização social formam sujeitos confrontados com a ampla difusão de repertórios de crítica em relação aos processos sociais da globalização. Tendo em vista a aspiração transversal pelo comum (Dardot \& Laval, 2015), especialmente nas lutas pelos espaços urbanos e pela crise dos sistemas de representação política acelerada nesta década, a análise da multidão difusa pelas redes da globalização implica o reconhecimento de novas formas e conteúdos políticos junto à ação coletiva produtora de singularidades.

As novas estruturas comunicativas do mundo e da vida propiciaram uma dispersão de públicos a partir de novas formas de integração simbólica (Habermas, 2003), de modo que os processos coletivos que tomaram ruas e praças ao redor do planeta dificilmente podem ser contidos sob a homogeneidade de uma massa. Trata-se, antes, de uma pluralidade composta de diferenças internas, movimentando-se pela infraestrutura capitalista. Michael Hardt e Antonio Negri (2017), que acabam de publicar um longo estudo sobre o ciclo de revoltas da atual década, analisam os movimentos a partir da instauração de uma ontologia plural que unifica a multiplicidade. Trata-se, aqui, das possibilidades de uma democracia constituinte (constituent democracy), articulando 
diferentes contextos locais a uma gramática comum capaz de instituir horizontes coletivos de reunião (assembly) e deliberação sobre a gestão do espaço e dos recursos disponíveis como plataformas críticas à financeirização e à precarização das formas de vida.

A multidão é o sujeito dessa nova instituição comum na medida em que ela incorpora a práxis política que emerge das redes. Nesse sentido, as novas multidões são singularidades concebidas com maior horizontalidade e mobilidade do que os fenômenos concentracionais de massa, indicando uma multiplicidade irredutível em sua constituição. À luz das dinâmicas transnacionais do valor e do capital, portanto, a desterritorialização das estruturas de reprodução do capitalismo cognitivo está vinculada à formação de subjetividades materializadas nos domínios da produção social. Com a ascensão do imaterial, da economia da informação e da reestruturação produtiva dos anos 1980 não são produzidos apenas bens, mas relações sociais e formas de vida construídas pelos mecanismos colaborativos dos processos de trabalho. Não ignorando a heterogeneidade das morfologias do trabalho com a interpenetração entre trabalho material e imaterial, a subproletarização das novas formas de precarização e a fragmentação da classe trabalhadora a partir da crise fordista dos anos 1970 (Antunes, 2009; Mészáros, 1995), a hegemonia qualitativa do trabalho imaterial (Hardt \& Negri, 2004, pp. 145-7) e de seus mecanismos de valorização indica tendências à produção e à reprodução social, situando a elaboração do terreno social em novas fronteiras e cadeias por meio da gestão de afetos, ideias e necessidades a partir de relações sociais e esferas de compartilhamento: bases, portanto, de uma produção biopolítica.

A estruturação do sistema social condiciona uma nova capacidade de difusão e de compartilhamento do comum para a socialização (commonality), integrando diversos campos (estruturas comunicativas, recursos naturais e mecanismos de cooperação) por meio dos quais a riqueza é produzida. Então, se o comum designa tanto os meios de produção quanto as formas de vida subjacentes a seu uso coletivo, os resultados das relações sociais elaboradas sobre esse princípio são formas nucleadas em novas arenas do político (Narita, 2018). Nesse sentido, se os comuns são alvos da financeirização e da apropriação neoliberal, a produção política da multidão implica um potencial horizonte de gerenciamento democrático de recursos combinando o humano com a infraestrutura não humana, o digital, o material e o imaterial (Hardt \& Negri, 2017). A produção desse comum, como relação social, indica justamente a força que emerge da globalização capitalista a partir da multiplicidade das redes e da circulação dos fluxos de pessoas e coisas no contexto biopolítico.

A multidão, portanto, é a subjetividade que emerge das singularidades, encontrando nas redes a forma dominante de organização da atividade coletiva. Os espectros da multidão não são fundamentados na unidade nem na identidade coerente do povo ou da massa, mas em um comum encontrado na interação de diferentes grupos sociais como singularidades (Hardt \& Negri, 2012). Informação, comunicação e cooperação constituem práticas normativas da racionalidade neoliberal na medida em que submetem as atividades produtivas a imperativos de socialização neoliberal (flexibilização, recicla- 
gem, capital humano, etc.), situando a nova produção sobre o campo do comum, ou seja, sobre a infraestrutura das redes de produtores em cooperação por meio da comunização (commoning) do trabalho vivo captado pelas estruturas do mercado. No entanto, longe de uma narrativa do triunfo da técnica no cosmopolitismo indiferenciado da aldeia global, as iluminações da racionalidade neoliberal repousam sobre as ruínas (Tsing, 2015) das periferias do capitalismo, compondo uma mesma imagem junto à lógica transnacional do valor na autonomização do sistema social.

Os levantes urbanos dos novos subalternos nas periferias do capitalismo global indicam pontos importantes nesse sentido, tendo em vista a racialização, a violência e a segregação social evidentes em Paris (2005), Londres (2011), Tottenham (2011) e no subúrbio de Husby em Estocolmo (2013), bem como a precarização dos piqueteros de Buenos Aires. Neste último caso, na esteira de uma série de protestos agravados desde 1996 à luz das mobilizações de desempregados e do que Alberto Bonnet chamou de "crise de convertibilidade" como resultado da disciplinarização imposta pelo mercado, as revoltas de dezembro de 2001, difundindo o célebre "que se vayan todos!" (cujo apelo destituinte, uma década depois, voltou a ecoar na Islândia, na Letônia e na Grécia), colocaram em circulação os repertórios de movimentos localizados a partir da cooperação e do compartilhamento junto a coletivos e a assembleias populares. A potência da multidão, aqui, respaldada por diversas formas associativas e uma pluralidade de estruturas de organização situadas à margem dos mecanismos tradicionais (sindicatos e partidos), implicou mecanismos de cooperação mobilizados sem um centro de co- ordenação ou uma liderança de vanguarda (Fontana et al., 2002).

A estruturação das forças da globalização capitalista, ao passo que cria e funciona sobre o comum (unificando circuitos transnacionais), pressupõe uma escala de assimetrias do processo de valorização do capital em centros e periferias. Samir Amin (2013), ao criticar a noção de multidão para o entendimento do ciclo de protestos dos anos 1990 e a nova agenda de revoltas urbanas aberta em 2008, tem razão ao sublinhar a globalização como processo de classe, destacando uma dinâmica que compõe estruturas funcionais de acumulação à luz da tendência da modernidade capitalista, a partir da segunda metade do século XIX, a proletarizar as populações tornando-as vendedoras de força de trabalho (seja pela subsunção formal ou pela subsunção real de Marx). Ainda que a tese da generalized proletarianization de Amin, expandindo o problema do proletariado para além do modelo fabril dos séculos XIX e $\mathrm{XX}$, perca de vista mediações importantes da sociedade da informação como condição pós-moderna da legitimação de saberes, a crise fordista e a automação implicaram uma nova onda de proletarização pela via direta (assalariamento de empregados) e indireta (subproletarização em tempo parcial, terceirização, etc.), de modo que a massa do setor informal altamente precarizada nas periferias, longe de vestígios de um passado anacrônico, indica a contraparte fundamental da modernidade capitalista.

Todavia, a dinâmica da multidão não pode ser reduzida a uma segmentação de classe tão estreita, uma vez que se trata de captar uma lógica transnacional de mobilização subjacente à formação das redes junto às tendências da infraestrutura capitalista glo- 
balizada. Com o imaterial e as estruturas de cooperação, as novas formas do "intelecto geral" de Marx deslocam os eixos de elaboração do valor no sentido de uma extração do comum (Hardt \& Negri, 2017), de modo que esse horizonte implica uma reconsideração da prática política e de sua invenção como multiplicidade unificada materialmente pela reinstituição do comum a partir da conexão entre o recurso e sua gestão coletiva (Narita, 2018). A multidão é, a um só tempo, produto e produtora das estruturas do campo biopolítico. Junto à produção de mercadorias e seus circuitos globais de valorização, então, há a produção de subjetividades dinamizadas pelas novas estruturas comunicativas do mundo da vida e pela produção de vínculos e demandas sociais.

Aqui, fundamental é a constituição da multiplicidade como sujeitos em movimento, já que a multidão é o "fazer-se" (making), ou seja, é a produção de subjetividades. Diferentemente da compactação moral das massas modernas, a multidão significa a produção de diferenças articuladas por singularidades conectadas, expondo uma multiplicidade capaz de conferir capilaridade ao agir comum (Brown \& Szeman, 2006). A globalização capitalista constitui uma nova forma global de poder na medida em que articula uma redefinição da soberania a novas bases materiais de produção e reprodução social (Hardt \& Negri, 2000, pp. 34-6). Nesse sentido, alicerçada sobre a administração da vida em todas as suas manifestações, a rede mista de poder que articula as estruturas dos Estados nacionais a mecanismos supranacionais de gestão da economia da população difunde hierarquias de gestão e conflito por meio de estruturas de controle. Assim, a dispersão de práticas de intervenção sobre singularidades mediante a subsunção real das formas de vida sob o capital (afetos, trabalho, gostos, etc.) redimensiona os antigos confinamentos disciplinares, organizando formas dispersas de controle que singularizam a socialização e tornam a totalidade da vida um objeto político.

Robert Kurz (2003) afirma que a multidão implica uma crítica do capitalismo sem uma crítica da forma do valor (ou seja, a forma fetichizada que faz do produto uma mercadoria), de modo que, como um marxisme de facteur subjectif, a multidão vira uma lógica puramente aditiva de processos sociais que, sem as mediações da forma social (por exemplo, uma crítica da própria categoria do trabalho, à la Moishe Postone, como atividade especificamente capitalista), reduz a sociedade a um afrontamento direto e imediato de puros sujeitos de vontade. A crítica, ao argumentar que a multidão é refém de uma lógica aditiva, perde de vista sua constituição dialética, ou seja, não se trata simplesmente da justaposição de quadros empíricos, mas do movimento de multiplicidades a partir do campo da produção biopolítica e das contradições da globalização capitalista. Ainda mais questionável no argumento de Kurz é a redução da multidão das periferias do capitalismo a uma "massa real de miseráveis que sequer é ligada pelo telefone", de modo que isso significa descartar o notável desenvolvimento transnacional da infraestrutura capitalista nas últimas duas décadas.

A multidão não é um produto espontâneo da produção social, mas um projeto de organização política da multiplicidade. Justamente por isso, a multidão não é um dado empírico previamente estabelecido pela simples agregação de corpos em massa. Como projeto político dinamizado por relações 
sociais do campo biopolítico construído pela racionalidade neoliberal, a multidão é, antes, uma maneira específica de estruturação da ação coletiva a partir de multiplicidades relacionadas ao comum.

O maior dinamismo das esferas de socialização da cidade torna a vida urbana o meio fundamental de enraizamento da multidão. A socialização da produção biopolítica junto ao imaterial e às redes nas cidades do capitalismo globalizado implica circuitos (comunicação, encontros, fluxos, compartilhamentos, etc.) em que a densidade dos contatos pode ser organizada politicamente por meio da metabolização dos conflitos e da exposição de hierarquias e formas de segregação (Hardt \& Negri, 2009, p. 249). As estruturas de comunicação multiplicam interconexões e redes na medida em que suas formas de controle e de produção de subjetividades tornam o conjunto da vida o centro de criação do valor. Se as massas são expressões por excelência das narrativas sobre a emergente constituição problemática da vida urbana (não à toa, encontrando ecos cada vez mais fortes nos imaginários sociais a partir da expansão capitalista dos anos 1840 e 1850), a multidão sinaliza as subjetividades em movimento, sobretudo, junto aos circuitos globais de produção do imaterial ancorados remota e materialmente nas cidades.

No fim dos anos 1970, Jean Baudrillard (1983) indicava o impacto das mídias e do sem-número de novos estímulos sociais fragmentários sobre as mutações dos fenômenos de massa, produzindo a dispersão de referentes no sistema de representação (o povo, a classe, o proletariado, etc.) e o esvaziamento de estruturas de coesão que conferiam transparência ao social. No entanto, o desdobramento da análise é bastante problemático: ao reduzir as mobilizações coletivas a uma passividade (convertendo todos os códigos en bloc em espetáculo), as "novas massas" já não teriam "uma história a escrever". A agregação in vacuo de indivíduos não construiria sujeitos e indicaria "o fim do social" como um vazio de significados, uma vez que o campo estaria confinado a temas-tópico de administração e gestão deslocado, assim, de grandes narrativas de emancipação. Baudrillard parece confundir a mutação estrutural nos fenômenos de massa com um esgotamento das estruturas de mobilização coletiva, obliterando qualquer entendimento do novo quadro histórico das manifestações multitudinárias e seu potencial de tematização social das críticas à globalização capitalista.

Enraizadas nas cidades, as multidões de 2008-2016 estão longe da passividade pressuposta por Baudrillard diante do espetáculo. Aqui, a dialética da sociedade de controle é plenamente desenvolvida a partir das práticas culturais: com um smartphone, a reprodução técnica ilimitada e o compartilhamento do imaterial, ao passo que misturam as fronteiras entre lazer/trabalho e cidadão/consumidor tornando a captura do valor expandida pelo processo vital (por meio de anúncios, adequação de gostos, algoritmos, etc.), igualmente possibilitam as transferências de repertórios de mobilização e a elaboração de subjetividades. Desde os anos 1960, Dallas Smythe intitulava esse processo de audience commodity, ou seja, sob o invólucro da passividade dos públicos, os atos de assistir, ler e usar tornaram-se geradores de valor-trabalho - nessa linha, a partir dos anos 1990, os teóricos das novas mídias, como Alvin Toffler, Christian 
Fuchs, George Ritzer e Nathan Jurgenson, têm chamado os novos públicos de "prossumidores" à luz do progressivo apagamento da separação entre produtores e consumidores na lógica intermitente do valor na esfera digital. Aliás, tendo em vista a prática política mais concreta, o próprio lugar do ciberativismo, desde o fim dos anos 1990 (Kahn \& Kellner, 2004), a partir dos protestos multitudinários no encontro do G8 em Colônia (Alemanha) e na reunião da Organização Mundial do Comércio em Seattle (Estados Unidos), indica a proatividade dos novos públicos na construção de relações políticas e sociais subjacentes à nova materialidade do capitalismo.

O tempo de revoltas aberto em 2008 implicou um "renascimento da história" (Badiou, 2012) na medida em que uma torção foi sinalizada no conflito social. Se o evento produz e difunde significados políticos mais amplos, ainda que os horizontes de expectativas (um tanto difusas, é verdade) das ruas sejam interpelados por um longo Termidor ou um vazio de tradução institucional junto aos sistemas representativos, as dinâmicas multitudinárias efetivaram espaços de elaboração e cooperação em situações não predicáveis (contextos incertos) a partir das quais mecanismos de imaginação política estiveram em curso. $\mathrm{O}$ ciclo de revoltas multitudinárias não implicou uma uniformização de lutas sociais, como repetições do mesmo, mas a tradução política e as transferências de estruturas de mobilização em relação a contextos integrados à globalização capitalista, elaborando formas de conexão e subjetividades políticas vinculadas à reunião (assemblage) na esfera pública e a novos potenciais democráticos de gestão e deliberação sobre o comum (Hardt \& Negri, 2017).
Não é exagero, portanto, afirmar que os fenômenos multitudinários demarcam inflexões significativas na modernidade global em diversas direções. As tendas e a multidão nas ruas de Tel Aviv, Haifa e Jerusalém em 2011, questionando os problemas de moradia e os custos de vida que pressionam as gerações mais jovens, apontaram justamente o fracasso da ideologia da abundância ilimitada e da retórica da ascensão capitalista, especialmente junto às aspirações de ampliação da classe média, à luz da precarização das formas de vida (trabalho, salário e instabilidade no emprego) e da crise de representação do sistema político (Rosenhek \& Shalev, 2014). Nas ruas brasileiras, a multidão de 2013, no lusco-fusco de uma década de desenvolvimento social e políticas públicas de inclusão, não apenas escancarou a crise de representação por meio de pautas morais de reconhecimento e pela precariedade de parte dos serviços públicos, mas questionou os custos do progresso indissociáveis dos esforços de invenção de um país apresentável ao mercado mundial (Cava, 2013) sob a ideologia da modernização na periferia do capitalismo (em uma conjuntura, aliás, marcada pela efetiva inserção do Brasil em grandes eventos internacionais entre 2007 e 2016). Colocada em perspectiva junto ao ciclo frenético de mobilizações (tanto à esquerda quanto à direta) e de disputas pelas ruas espalhadas pelo país entre 2013 e 2016, a multidão indicou as fraturas do ciclo progressista do capitalismo razoavelmente pavimentado desde meados dos anos 1990.

A análise das multidões capta contradições fundamentais que movem o sistema social. Traduzida para a prática política, as novas morfologias das revoltas urbanas a partir de 2008 indicaram potenciais saídas 
de esquemas dualistas entre massas e liderança, espontaneísmo e centralismo, democracia e autoridade, público e privado, etc., evidenciando como os movimentos sociais e a instituição de um campo comum estiveram correlacionados em agendas críticas à racionalidade neoliberal. Mais do que flash mobs politizados, o ciclo de manifestações multitudinárias desta década trouxe à tona uma consistência própria que, emergindo das estruturas de cooperação e da infraestrutura de redes, escancarou o horizonte comum de contradições ao passo que indicou condições de um novo internacionalismo.

\section{BIBLIOGRAFIA}

AMIN, Samir. Three essays on Marx's value theory. Nova York, Monthly Review Press, 2013.

ANTUNES, Ricardo. Os sentidos do trabalho. São Paulo, Boitempo, 2009.

ARANTES, Paulo. O novo tempo do mundo. São Paulo, Boitempo, 2014.

BADIOU, Alain. The rebirth of history: times of riots and uprisings. Trad. Gregory Elliott.

Nova York, Verso, 2012.

BAUDRILLARD, Jean. In the shadow of the silent majorities, or the end of the social.

Trad. Paul Foss. Nova York, Semiotext(e), 1983.

BRANTLINGER, Patrick. States of emergency: essays on culture and politics. Indianapolis, Indiana University Press, 2013.

BROWN, Nicholas; SZEMAN, Imre. "O que é a multidão?", in Novos Estudos Cebrap, v. 75,

São Paulo, 2006.

CANETTI, Elias. Masse und Macht: wesentliche Zusammenhänge zum Verständnis unseres Zeitalters. Frankfurt am Main, Fischer, 2001.

CAVA, Bruno. A multidão foi ao deserto. São Paulo, Annablume, 2013.

DARDOT, Pierre; LAVAL, Christian. A nova razão do mundo: ensaio sobre a sociedade neoliberal. Trad. Mariana Echalar. São Paulo, Boitempo, 2016.

FEIGENBAUM, Anna. Tear gas: from the battlefields of WWI to the streets of today. Nova York, Verso, 2017.

FISCHER, Tony. "Performance and the tragic politics of the agon", in Performing antagonism: theatre, performance and radical democracy. Londres, Palgrave Macmillan, 2017.

FONTANA, Edgardo et al. 19 y 20: apuntes para el nuevo protagonismo social. Buenos Aires, Ediciones de Mano en Mano, 2002. 
HABERMAS, Jürgen. "Aus Katastrophen lernen? Ein zeitdiagnostischer Rückblick auf das

kurze 20. Jahrhundert", in Zeitdiagnosen. Frankfurt am Main, Suhrkamp, 2003.

HARDT, Michael; NEGRI, Antonio. Assembly. Oxford, Oxford University Press, 2017. Commonwealth. Cambridge, Harvard University Press, 2009.

Declaration. Nova York, Argo Navis, 2012.

Empire. Cambridge, Harvard University Press, 2000.

Multitude. Londres, Penguin, 2004.

JOHNSON, Matthew; SULIMAN, Samid. Protest: analysing current trends. Londres, Routledge, 2015.

KAHN, Richard; KELLNER, Douglas. "New media and internet activism: from the Battle of Seatle to blogging", in New Media \& Society, v. 6, n. 1, 2004.

KECHAVARZI-TEHRANI, Dariouche. "Teargas colonialism", in The Funambulist, v. 14, Paris, 2017.

KLEIN, Naomi. "Reclaiming the commons", in New Left Review, v. 9, 2002.

KURZ, Robert. "Empire: le monde en crise comme Disneyland de la multitude", in Les habits neufs de l'empire: remarques sur Negri, Hardt et Rufin. Paris, Léo Scheer, 2003.

MÉSZÁROS, István. Beyond capital. Nova York, Merlin Press, 1995.

MORELOCK, Jeremiah; NARITA, Felipe Ziotti. "Public sphere and world-system: theorizing populism at the margins", in Critical theory and authoritarian populism. Londres, University of Westminster Press, 2018 (no prelo).

NARITA, Felipe Ziotti. "Unlimited capitalism and the politics of the common", in Praktyka Teoretyczna, vol. 26, Poznan, 2018 ("Cooperation as the institution of the common" Org. Bartłomiej Błesznowski e Mikołaj Ratajczak).

PABST, Adrian. "The resurgence of the civic", in Possible Futures (Social Science Research Council). Nova York, 13/dez./ 2011.

PELBART, Peter Pál. O avesso do niilismo: cartografias do esgotamento. São Paulo, N-1 Edições, 2013.

ROSENHEK, Zeev; SHALEV, Michael. "The political economy of Israel's social justice protests", in Contemporary Social Science, v. 9, Londres, 2014.

SASSEN, Saskia. "The global street: making the political", in Globalizations, v. 8, n. 5, Nova York, 2011.

SLOTERDIJK, Peter. O desprezo das massas: ensaio sobre as lutas culturais na sociedade moderna. Trad. Claudia Cavalcanti. São Paulo, Estação Liberdade, 2016.

TSING, Anna Lowenhaupt. The mushroom at the end of the world: on the possibility of life in capitalist ruins. Princeton, Princeton University Press, 2015.

VIRNO, Paolo. Grammatica della moltitudine. Roma, Rubettino, 2001. 